\title{
Efeito de condicionamento mecânico no controle de porte e qualidade de crisântemo evasado
}

\author{
DENISE LASCHI ${ }^{1}$ e PRISCILA SILVÉRIO ${ }^{1}$
}

\section{RESUMO}

O crisântemo (Dendranthema grandiflorum Ramat Kitam.) é uma planta originária do Japão e pertence à família das asteráceas. É uma das plantas ornamentais mais comercializadas, por três motivos principais: precisão com que responde ao fotoperíodo, diversidade de tipos e cores de flores e durabilidade da flor. Seu cultivo em vaso exige, além de poda, uso de reguladores para o controle mais efetivo do porte. Há algum tempo, vem-se "tentando substituir o uso de substâncias químicas para regular o crescimento pelo uso de condicionamento mecânico", que seria feito mediante uma perturbação física em partes da planta, resultando em uma resposta mecânica a esse estresse, que normalmente se apresenta na forma de inibição do crescimento em massa e dimensão da maioria das partes da planta. $\mathrm{O}$ presente trabalho teve como objetivo testar o uso do condicionamento mecânico, comparando-o a um regulador de crescimento e a uma testemunha não submetida a nenhum tipo de tratamento para o controle de porte de crisântemo cultivado em vaso. Foi conduzido em casa de vegetação do Departamento de Horticultura, FCA-Unesp, a partir de março de 1999. As plantas foram submetidas aos seguintes tratamentos: $\mathrm{T} 1$ = Testemunha; $\mathrm{T} 2$ = ácido succínio2,2 dimetilidrazido (SADH) 0,25\%; T3 = Estresse mecânico a partir da quarta semana do ciclo, uma vez por dia; T4 = Estresse mecânico a partir da quarta semana do ciclo, duas vezes por dia; T5 = Estresse mecânico a partir da sexta semana do ciclo, uma vez por dia; T6 = Estresse mecânico a partir da sexta semana do ciclo, duas vezes por dia. Com base nos resultados, concluiu-se que o uso de condicionamento mecânico diminuiu significativamente o porte das plantas e a aplicação precoce e a maior quantidade diária aplicada aumentou o efeito do tratamento de condicionamento mecânico; o SADH foi o tratamento que produziu as menores plantas. O condicionamento mecânico não afetou o diâmetro de flores e o número de folhas e flores, indicando que esses tratamentos não alteraram a qualidade das plantas produzidas.

Palavras-chave: (Dendranthema grandiflorum Ramat Kitam.); controle de porte; reguladores de crescimento; estresse.

\section{ABSTRACT \\ Título em inglês}

The chrysanthemum (Dendranthema grandiflorum Ramat Kitam.) is an original plant of Japan belonging to Asteraceae family. It is one of the most marketed ornamental plants, for three main reasons: response precision to the photoperiod, diversity of types and colors of flowers and durability of the flower. The chrysanthemum cultivation in vase demands, besides the pruning, the use of regulators for the more effective control of the height. Researchers are "trying to substitute the use of chemical substances to regulate the growth by the use of mechanical conditioning", that would be done through a physical disturbance in parts of the plant resulting in a mechanical response to this stress, that usually comes in the form of inhibition of the growth in mass and dimension of most of plants parts. The present experiment had as objective to study the influence of stress, comparing to a growth regulator to control chrysanthemum height. The work was installed in pots under greenhouse conditions (Vegetal Production Department -Horticulture, FCA/Unesp), in March of 1999. The plants were submitted to the fol-

${ }^{1}$ Departamento de Produção Vegetal, Faculdade de Ciências Agronômicas (FCA-UNESP), Caixa Postal 237, 18603-970, Botucatu (SP). 
lowing treatments: $\mathrm{T} 1=$ witness; $\mathrm{T} 2=\mathrm{SADH}$ (succinic acid - 2.2- dimethyl hydrazide) $(0,25 \%)$; T3 = mechanical stress, starting from the fourth week, once a day; T4 = mechanical stress, starting at the fourth week, twice a day; T5 = mechanical stress, starting at the sixth week, once a day; T6 = mechanical stress, twice a day. The results, led to the following conclusions: the stress decreased significantly the height of the plants; the precocious application of the stress increases the response, and this presents a larger response as larger the amount of stress applied daily; SADH was the treatment that produced the smallest plants; the stress, didn't have deleterious effect in the qualitative parameters of the plants (production of flowers and leaves), that is, didn't decrease the quality of the produced plants.

Keywords: (Dendranthema grandiflorum Ramat Kitam.); potted mums; height control; growth regulators; mechanical stress.

\section{INTRODUÇÃO}

O crisântemo (Dendranthema grandiflorum ramat Kitam.), planta originária do Japão, é uma das plantas ornamentais mais comercializadas no Brasil, por três motivos principais: precisão com que responde ao fotoperíodo, diversidade de tipos e cores de flores e durabilidade da flor (LOPES, 1977).

Esta planta tem sido produzida para comercialização em vaso ou cortada, contando, para isso, com diferentes métodos de cultivo e variedades.

O cultivo de crisântemo em vaso exige variedades adaptadas para esse uso específico e, assim, para que se obtenha tamanho adequado, que deve ser 2,0 a 2,5 vezes a altura do vaso (LARSON,1980), faz-se uso de reguladores de crescimento usados comercialmente (Ball,1985, citado por REISS-BUBENHEIM \& LEWIS, 1986).

Cathey (1967), citado por WEAVER (1982), relatou o uso do SADH (ácido succínico 2,2 dimetilidrazida) em aspersão foliar, em concentrações de 2.500 a 5.000 ppm, como um produto efetivo na redução de porte de crisântemo em vaso.

A prática da poda do ápice da planta também reduz a altura da planta, mas esta é associada ao uso de reguladores no caso de cultivo em vaso, para um controle mais efetivo.

Há algum tempo, vem-se tentando substituir o uso de substâncias químicas pelo condicionamento mecânico para regular o crescimento da planta, o qual seria feito por meio de uma perturbação física em partes da planta, resultando em uma resposta mecânica dessa planta. Tal condicionamento normalmente se apresenta na forma de inibição do crescimento em massa e dimensão da maioria das partes da planta (LATIMER,1991).

Tal condicionamento pode ser obtido mediante resposta ao estresse mecânico ao tato (toque, fricção,etc.) chamado de tigmomorfogênese (JAFFE, 1973) e estresse mecânico não táctil (chacoalhar, vibrar, etc.), chamado de seismomorfogênese (MITCHELL et al., 1975).

O mecanismo de resposta ao estresse mecânico não é bem conhecido, mas alguns autores já o associaram a vários reguladores. TAKAHASHI \& JAFFE (1984), ao testarem tigmomorfogênese em soja, notaram que plantas estressadas apresentavam um aumento de produção de etileno. Chocalhar ramos de pêra pode inibir o transporte polar de auxinas (MITCHELL, 1977). O estresse pode também diminuir a quantidade de giberelina, como foi demonstrado por CAULA \& MITCHELL (1983) em girassol. Esse efeito pode ser o responsável pela redução em elongação do ramo e expansão de folhas, dado comprovado também por BEYL \& MITCHELL (1977a).

Quando comparado a outros métodos de redução de altura, os resultados do condicionamento mecânico em plantas parecem muito similares aos obtidos com tratamento com daminozide (SADH) ou chlormequat (CCC), fato observado por vários autores (BEYL \& MITCHELL, 1977b; BIDDINGTON \& DEARMAN, 1985).

A resposta ao estresse é maior em tecidos jovens ou tecidos diretamente contatados pelos tratamentos (Turgoron et al, 1977, citado por LATIMER, 1991). Plantas jovens também respondem melhor, o que indica que o tempo de iniciação do tratamento pode afetar a resposta (Latimer, 1991, citado por LATIMER, 1991), assim como a duração e o momento de aplicação do tratamento (BEYL \& MITCHELL, 1977a; MITCHELL, 1977).

MITCHELL (1996) relata que o condicionamento mecânico promove a redução do comprimento do ramo, área foliar e peso seco do ramo em vários vegetais. Essa redução pode variar de 25 a $43 \%$, dependendo do momento em que se inicia o tratamento.

O mesmo autor relata que as giberelinas são hormônios que apresentam a maior correlação com 
o uso de estresse mecânico. Os tecidos que receberam os tratamentos tiveram uma grande perda de giberelina. TAKAHASHI \& SUGE (1980) relataram que o uso da combinação de GA4+GA7 anulou a resposta ao estresse mecânico em plantas de abóbora (Cucumis sativus).

O presente trabalho teve como objetivo verificar o efeito do uso do estresse mecânico, comparado a um regulador de crescimento e a uma testemunha, no controle de porte e qualidade de crisântemo cultivado em vasos.

\section{MATERIAL E MÉTODOS}

O presente trabalho foi conduzido em casa de vegetação do Departamento de Horticultura da Faculdade de Ciências Agronômicas da Universidade Estadual Paulista - UNESP - Câmpus de Botucatu.

O experimento foi instalado em 8 de março de 1999. Para sua implantação, utilizaram-se 60 vasos plásticos $(1 \mathrm{~L})$, preenchidos com uma mistura de terra vermelha, xaxim, casca de pínus e esterco de curral na proporção $5: 2: 2: 1$. A esta mistura adicionou-se calcário calcítico $\left(6,0 \mathrm{~kg} / \mathrm{m}^{3}\right)$, nitrato de cálcio especial $\left(1,5 \mathrm{~kg} / \mathrm{m}^{3}\right)$ e superfosfato triplo $\left(0,75 \mathrm{~kg} / \mathrm{m}^{3}\right)$. Seis mudas não enraizadas de crisântemo foram plantadas em cada vaso e, durante o enraizamento, receberam uma adubação de nitrato de cálcio $(268,8 \mathrm{~g} / \mathrm{L})$, nitrato de amônio $(93,8 \mathrm{~g} / \mathrm{L})$, MAP $(75 \mathrm{~g} / \mathrm{L})$ e sulfato de amônio $(62,5 \mathrm{~g} / \mathrm{L})$.

Os vasos foram transferidos para a casa de vegetação 20 dias após o plantio, com as plantas já submetidas ao "pinching" (poda de ponteiro), os quais foram dispostos em duas bancadas com 30 vasos cada um. Em seguida, receberam a primeira irrigação e uma identificação de tratamento, feita por sorteio.

O experimento contou com seis tratamentos dispostos em delineamento experimental de blocos casualizados com dez repetições, onde cada vaso foi considerado uma parcela.

Os tratamentos foram iniciados no dia seguinte à instalação e receberam as seguintes denominações:

- $\mathrm{T}_{1}$ : Plantas que não sofreram nenhum tratamento para controle de porte.

- $\mathrm{T}_{2}$ : Pulverização com SADH (ácido succínico $-2,2$ dimetilidrazida).

- $\quad \mathrm{T}_{3}$ : Estresse mecânico - tigmomorfogênese (passar pano sobre as folhas uma vez ao dia) a partir da quarta semana do ciclo.
- $\mathrm{T}_{4}$ : Estresse mecânico - tigmomorfogênese (passar pano sobre as folhas duas vezes ao dia) a partir da quarta semana do ciclo.

- $\mathrm{T}_{5}$ : Estresse mecânico - tigmomorfogênese (passar pano sobre as folhas uma vez ao dia) a partir da sexta semana do ciclo.

- $\mathrm{T}_{6}$ : Estresse mecânico - tigmomorfogênese (passar pano sobre as folhas duas vezes ao dia), a partir da sexta semana do ciclo.

Durante o experimento, não foi necessário o uso de um sistema de iluminação/escurecimento para indução floral, pois, no período da condução, o fotoperíodo era adequado para a indução floral.

As mudas enraizadas foram obtidas de matrizes da variedade "Braga" (tipo margarida, de coloração vermelha), cuja característica é o porte alto.

$\mathrm{O}$ regulador de crescimento utilizado foi o SADH (ácido succínico - 2,2 - dimetilidrazida), encontrado no mercado com o nome de Alar ou Bnine, numa solução de $0,25 \%$, mais $1,0 \mathrm{~mL}$ de óleo vegetal. A aplicação foi feita por via foliar (área foliar total), quando as plantas estavam na sexta semana do ciclo, após o "pinching" (poda dos ponteiros), usando-se um pulverizador manual. Aplicou-se o regulador durante quatro semanas consecutivas, três vezes por semana.

Efetuou-se o controle fitossanitário semanalmente, com produtos recomendados para a cultura. Durante a condução do experimento, não se observaram problemas com pragas e doenças.

Realizou-se uma adubação diária com fertilizantes distintos de acordo com a fase de desenvolvimento do crisântemo.

A irrigação das plantas foi diária e manual, 50 $\mathrm{ml} / \mathrm{vaso}$.

O tratamento com estresse foi finalizado na fase de abertura floral para que não houvesse danos às flores.

Com o objetivo de avaliar a redução de porte segundo o estresse mecânico, efetuaram-se as seguintes medidas, após a abertura das flores: número de folhas; número de flores; número de botões; área foliar, em $\mathrm{cm}^{2}$ (medida por meio de Automatic Area Meter, modelo - AAM-7, HAYASHI DENKO CO. LTD.); comprimento da parte aérea, em cm; comprimento de entrenós, em mm; diâmetro das flores, em $\mathrm{mm}$; massa seca do caule, em mg; massa seca das folhas, em mg; massa seca das flores, em mg; altura total dos vasos, em cm (para essa medida, levou-se em consideração o vaso e a planta). 
Para a avaliação dos resultados, os dados obtidos foram submetidos à análise da variância por contrastes, sendo as médias comparadas pelo teste de Tukey, utilizando-se o nível de significância de 5\%.

\section{RESULTADOS E DISCUSSÃO}

A Tabela 1 apresenta a análise da variância para todos os parâmetros avaliados em plantas de crisântemo submetidas aos tratamentos para controle de porte.

Os resultados indicam contrastes significativos para os parâmetros relacionados com o porte das plantas, o que leva a crer que os tratamentos testados tiveram algum efeito no controle da altura das plantas, e interferiram fisiologicamente nos mecanismos que atuam na redução de seu porte. Tais mecanismos de resposta não são bem conhecidos, mas autores já o associaram a vários reguladores. TAKAHASHI \& JAFFE (1984), ao testarem tigmomorfogênese em soja, notaram que plantas submetidas a estresse apresentavam um aumento de produção de etileno. Chocalhar ramos de pêra pode inibir o transporte polar de auxinas (MITCHELL, 1977). $\mathrm{O}$ estresse pode também diminuir a quantidade de giberelina, como foi demonstrado por CAULA \& MITCHELL (1983) em girassol. Esse efeito pode ser o responsável pela redução em alongamento do ramo e expansão de folhas.

O teste de médias (Tabela 2) para comprimento de entrenós, comprimento da parte aérea, altura total do vaso, apresentou respostas semelhantes, tendo o uso do SADH a menor média e a testemunha, a maior para os três parâmetros citados. Ao analisar o efeito do estresse, notou-se que houve resposta significativa para os três parâmetros, sendo o mais efetivo o estresse no começo do ciclo, duas vezes ao dia. É interessante notar que a resposta ao estresse, quando aplicado no início do ciclo, é quantitativa, ou seja, quanto maior o estímulo, maior a resposta. Quando a aplicação é iniciada no meio do ciclo, porém, a quantidade de estresse diário (uma ou duas vezes) apresenta resposta uniforme, sendo igualmente intermediária nos tratamentos de estresse no início aplicados uma vez ou duas vezes ao dia.

Esse dado concorda com aqueles encontrados por LATIMER (1991); BEYL \& MITCHELL (1977b); MITCHELL (1977); LASCHI \& ARAKI (1995) e outros para os quais o momento em que é iniciado o tratamento é importante, e, quanto mais cedo, maior a sensibilidade. Segundo LATIMER (1991), entretanto,maior sensibilidade ao estresse ocorre em tecidos jovens ou tecidos diretamente atingidos pelos tratamentos. Há também melhor resposta em plantas jovens.

Quanto à resposta ao número de estímulos aplicados, apenas o tratamento iniciado no começo do ciclo apresentou um efeito cumulativo, ou seja, quanto mais estímulos (um ou dois) maior a resposta, fato que está de acordo com vários pesquisadores (BEYL \& MITCHELL, 1977a; MITCHELL, 1977), para os quais a duração do estímulo afeta a resposta. Quando a aplicação do estresse se inicia no meio do ciclo, apesar da redução de porte quando comparada à testemunha, não há diferença quanto ao número de estímulos aplicados diariamente.

Para parâmetro massa seca de caule houve maior uniformidade de resposta, diferindo dos demais, apenas o tratamento com SADH. Trata-se de um dado bastante interessante, visto indicar que a aplicação de estresse não diminuiu a quantidade de massa seca do caule, quando comparado com a testemunha. LASCHI \& ARAKI (1995) trabalhando com estresse, também constataram que o SADH reduziu a massa seca de caule.

Na Tabela 3, têm-se as médias e o resultado do teste de médias para os parâmetros de qualidade do vaso, ou seja, o número de botões, a massa seca total de flores e o número de folhas. Os parâmetros seguintes: número de flores, diâmetro de flores, peso seco de folhas e área foliar não aparecem nesse quadro por não apresentarem diferenças significativas no teste da variância (Tabela 1).

Para o parâmetro número de folhas tem-se que a testemunha e o $\mathrm{SADH}$ produziram menor número de folhas, o que diferiu significativamente do estresse no início do ciclo uma vez por dia, o qual apresentou maior número de folhas, mas não diferiu dos demais tratamentos. Esse dado é interessante tendo em vista que a testemunha, apesar de apresentar parâmetros de porte (CI, CPA, AT, MSC) bem superiores aos demais tratamentos, não produziu maior número de folhas. Já o SADH reduziu o número de folhas, quando comparadas ao estresse no início uma vez por dia. Esse dado indica que o estresse não atua prejudicando a qualidade da planta produzida, quando comparado ao $\mathrm{SADH}$ e à testemunha. Esses dados confirmam os encontrados por LASCHI \& ARAKI (1995) e LATIMER (1991). 


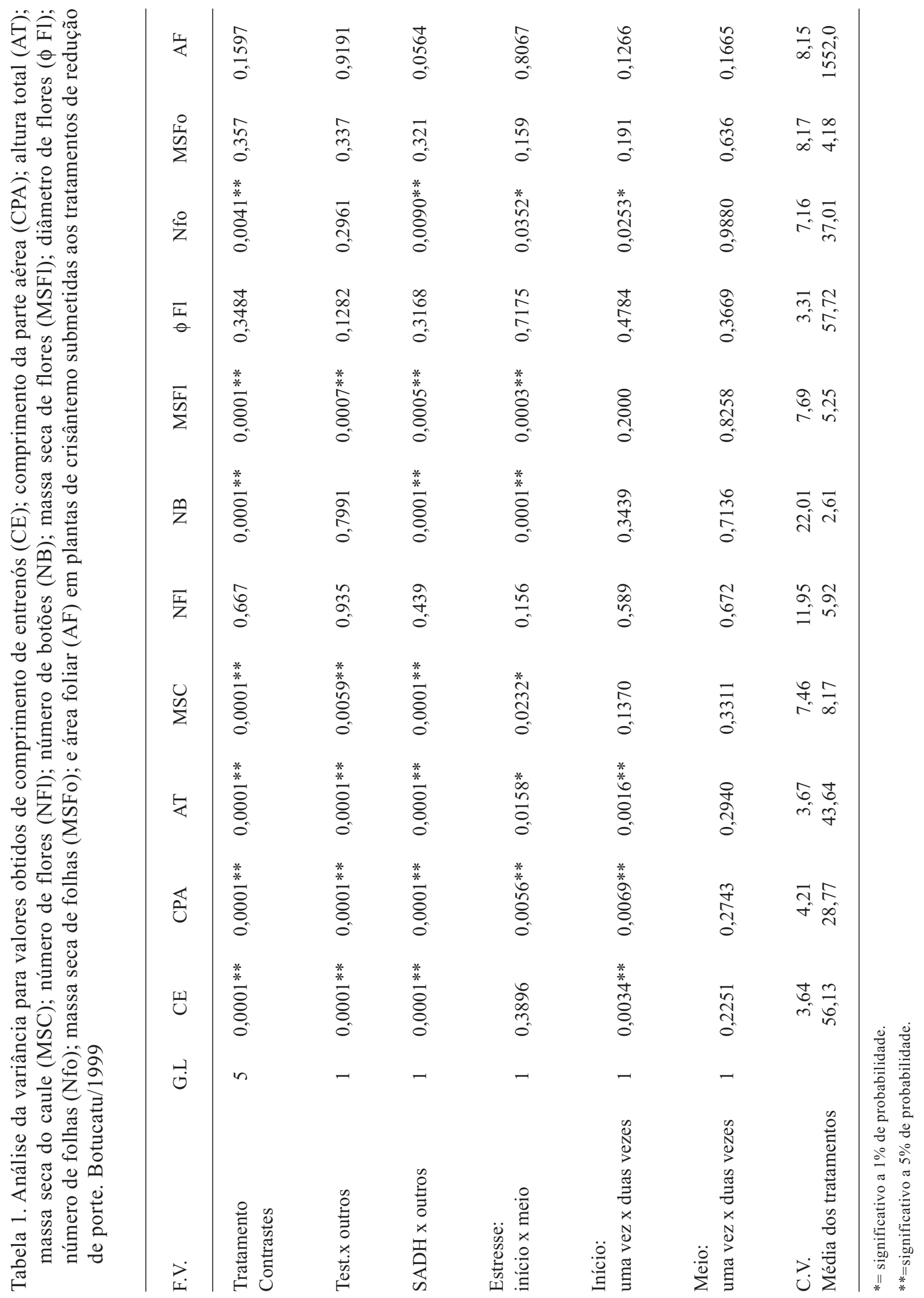


Tabela 2. Médias obtidas para comprimento de entrenós, em $\mathrm{mm}$ (CE); comprimento da parte aérea, em $\mathrm{cm}$

(CPA); altura total - vaso+planta, em cm (AT); massa seca do caule, em mg (MSC) de plantas de crisântemo submetidas aos tratamentos para controle de porte. Botucatu/1999

\begin{tabular}{|c|c|c|c|c|}
\hline Tratamentos & $\mathrm{CE}$ & CPA & AT & MSC \\
\hline Testemunha & $69,96 \mathrm{~A}$ & $33,33 \mathrm{~A}$ & $48,74 \mathrm{~A}$ & $8,68 \mathrm{~A}$ \\
\hline SADH & $37,26 \mathrm{D}$ & $29,13 \mathrm{D}$ & $37,88 \mathrm{D}$ & $6,50 \mathrm{~B}$ \\
\hline Estresse $4^{\mathrm{a}}$. sem/ uma vez & $61,41 \mathrm{~B}$ & $27,60 \mathrm{BC}$ & $44,37 \mathrm{~B}$ & $8,44 \mathrm{~A}$ \\
\hline $4^{\mathrm{a}} . \mathrm{sem} / \mathrm{duas}$ vezes & $54,39 \mathrm{C}$ & $23,62 \mathrm{C}$ & $41,97 \mathrm{C}$ & $8,03 \mathrm{~A}$ \\
\hline Estresse $6^{\mathrm{a}}$. sem/ uma vez & $58,06 \mathrm{BC}$ & $29,78 \mathrm{~B}$ & $44,82 \mathrm{~B}$ & $8,51 \mathrm{~A}$ \\
\hline $6^{\mathrm{a}} . \mathrm{sem} /$ duas vezes & $55,39 \mathrm{BC}$ & $29,18 \mathrm{BC}$ & $44,06 \mathrm{BC}$ & $8,82 \mathrm{~A}$ \\
\hline
\end{tabular}

Médias de uma mesma coluna, seguidas da mesma letra não diferem entre si pelo teste de Tukey a 5\% de probabilidade.

Tabela 3.Médias obtidas para número de botões (NB); massa seca de flores, em mg (MSF1) e número de folhas (Nfo) de plantas de crisântemo submetidas aos tratamentos para controle de porte. Botucatu/1999

\begin{tabular}{|c|c|c|c|}
\hline Tratamentos & NB & MSF1 & Nfo \\
\hline Testemunha & $2,65 \mathrm{BC}$ & $5,68 \mathrm{~A}$ & $36,20 \mathrm{~B}$ \\
\hline SADH & $3,88 \mathrm{~A}$ & $4,82 \mathrm{C}$ & $34,92 \mathrm{~B}$ \\
\hline Estresse $4^{\mathrm{a}}$. sem/ uma vez & $2,81 \mathrm{~B}$ & $5,13 \mathrm{BC}$ & $40,02 \mathrm{~A}$ \\
\hline $4^{\mathrm{a}}$. sem/ duas vezes & $2,57 \mathrm{BCD}$ & $4,89 \mathrm{C}$ & $37,27 \mathrm{AB}$ \\
\hline Estresse $6^{a}$. sem/ uma vez & $1,83 \mathrm{D}$ & $5,53 \mathrm{AB}$ & $36,83 \mathrm{AB}$ \\
\hline $6^{\mathrm{a}} . \mathrm{sem} / \mathrm{duas}$ vezes & $1,93 \mathrm{CD}$ & $5,49 \mathrm{AB}$ & $36,82 \mathrm{AB}$ \\
\hline
\end{tabular}

Médias de uma mesma coluna, seguidas da mesma letra não diferem entre si pelo teste de Tukey a 5\% de probabilidade.

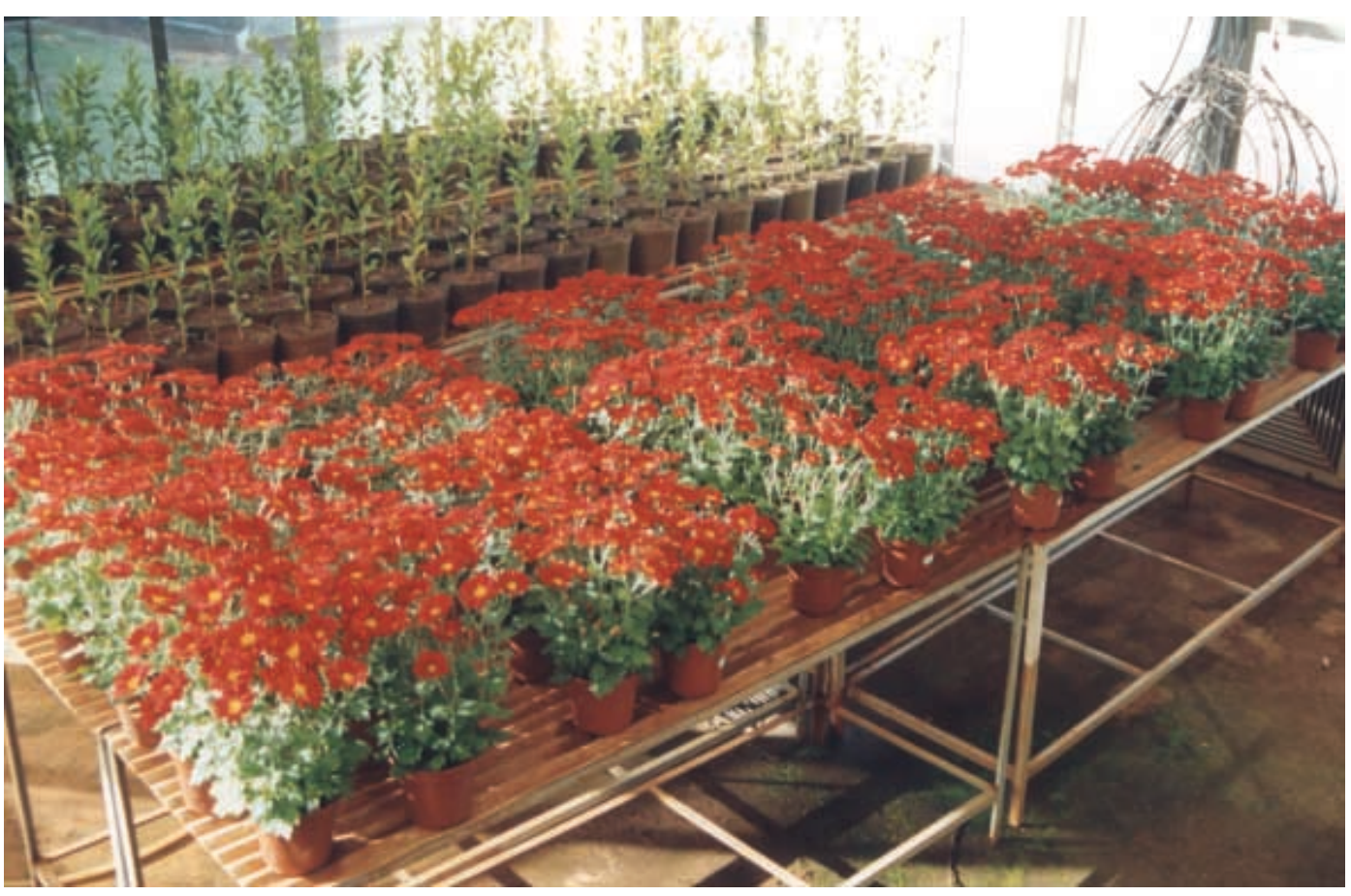

Figura 1. Vista geral dos tratamentos. Da esquerda para a direita: testemunha; SADH; estresse no início do ciclo, uma vez ao dia; estresse no início do ciclo duas vezes ao dia; estresse no meio do ciclo uma vez ao dia; estresse no meio do ciclo, duas vezes ao dia. 


\section{CONCLUSÕES}

Tomando-se por base os resultados, concluiu-se que o estresse mecânico diminuiu significativamente o porte das plantas e a aplicação precoce e o maior número de aplicações diárias aumentou o efeito do estresse. O SADH foi o tratamento que produziu as menores plantas e o estresse não afetou o diâmetro e o número de folhas e flores. Isto pode indicar que esses tratamentos não alteraram a qualidade das plantas produzidas.

\section{BIBLIOGRAFIA}

BEYL, C.A. \& MITCHELL, C.A. Automated mechanical stress application for height control of greenhouse chysanthemum. HortScience, Alexandria, v.12, n.6, p.575-577, 1977a.

BEYL, C.A. \& MITCHELL, C.A. Characterization of mechanical stress dwarfing in chrysanthemum. J. Am. Soc. Hortic. Sci., Alexandria, v.102, n.5, p.591-594, 1977b.

BIDDINGTON, N.L. \& DEARMAN, A.S. The effect of mechanically induced stress on the growth of cauliflower, lettuce and celery seedlings. Ann. Bot., London, v.55, p.109-119, 1985.

CAULA, A.B. \& MITCHELL, C.A. Alteration of growth exudation rate, and endogenous hormones profiles in mechanically dwarfed sunflower.J. Am. Soc. Hortic. Sci., Alexandria, v.108, n.2, p.257-262, 1983.

JAFFE, M.J. Thigmomorphogenesis: the response of plant growth and development to mechanical stimulation. Planta, Berlin, v. 114, p.143-157, 1973.

LARSON, R.A. Introduction to Horticulture. North Carolina: Academic Press, 1980. 607p.
LASCHI, D. \& ARAKI, T.N. Aplicação de estresse no controle de porte de crisântemo cultivado em vaso. In: CONGRESSO BRASILEIRO DE FLORICULTURA E PLANTAS ORNAMENTAIS, 10., Campinas, Anais... Campinas, 1995. p.14.

LATIMER, J.G. Mechanical conditioning for control of growth and quality of vegetable transplants. HortScience, Alexandria, v.26, n.12, p.1456-1461, 1991.

LOPES, L.C. O cultivo do crisântemo. Viçosa: Universidade Federal de Viçosa, Minas Gerais, 1977. 13p. (Boletim Técnico)

MITCHELL, C.A. Influence of mechanical stress on auxin stimulated growth of excised pea stem section. Physiol. Plant., Copenhagen, v.41, p.129-134, 1977.

MITCHELL, C.A. Recent advances in plant response to mechanical stress: theory and application. HortScience, Alexandria, v.31, n.1, p.31-35, 1996.

MITCHELL, C.A.; SEVERSON, J.A.; WOTT, J.A. \& HAMMER, P.A. Seismomorphogenic regulation of plant growth. J. Am. Soc. Hortic. Sci., Alexandria, v.100, p.161-165, 1975.

REISS-BUBENHEIM, D. \& LEWIS, A.J. Pre-plant application of growth retardants to pinched and unpinched chysanthemum cuttings. Sci. Hortic., Amsterdam, v.28, p.159-164, 1986.

TAKAHASHI, H. \& JAFFE, M.J. Thigmomorphogenesis: the relationship of mechanical perturbation to elicite-like activity and ethylene production. Physiol. Plant., Copenhagen, v.61, p.405-411, 1984.

TAKAHASHI, H. \& SUGE, H. Sex expression in cucumber plants as affected by mechanical stress. Plant and cell Physiology, Tokio, v.21, p. 303-310, 1980.

WEAVER, R.J. Reguladores del crecimiento de las plantas en la Agricultura. México: Editorial Trillas, 1982. 622p. 